\title{
Synergistic interaction of novel lactate dehydrogenase inhibitors with gemcitabine against pancreatic cancer cells in hypoxia
}

\author{
M Maftouh ${ }^{1,5}$, A Avan $^{1,5}, \mathrm{R}$ Sciarrillo ${ }^{1}, \mathrm{C}$ Granchi ${ }^{2}, \mathrm{~L} \mathrm{G}$ Leon $^{3}, \mathrm{R} \mathrm{Rani}^{2}, \mathrm{~N} \mathrm{Funel}^{4}, \mathrm{~K} \mathrm{Smid}{ }^{1}$, R Honeywell ${ }^{1}$, \\ U Boggi ${ }^{4}$, F Minutolo ${ }^{2}$, G J Peters ${ }^{1}$ and E Giovannetti ${ }^{*}, 1$ \\ ${ }^{1}$ Department of Medical Oncology, VU University Medical Center, De Boelelaan 1117, 1081HV, Amsterdam, Netherlands; \\ ${ }^{2}$ Department of Pharmacy, University of Pisa, Pisa, Italy; ${ }^{3}$ Center for Biomedical Research of the Canary Islands, Instituto de \\ Tecnologias Biomedicas, University of La Laguna, La Laguna, Spain and ${ }^{4}$ Department of Surgery, University of Pisa, Pisa, Italy
}

Background: Hypoxia is a driving force in pancreatic-ductal-adenocarcinoma (PDAC) growth, metastasis and chemoresistance. The muscle-isoform of lactate dehydrogenase (LDH-A) constitutes a major checkpoint for the switch to anaerobic glycolysis, ensuring supply of energy and anabolites in hypoxic-environments. Therefore, we investigated the molecular mechanisms underlying the pharmacological interaction of novel LDH-A inhibitors in combination with gemcitabine in PDAC cells.

Methods: Lactate dehydrogenase A levels were studied by quantitative RT-PCR, western blot, immunofluorescence and activity assays in 14 PDAC cells, including primary-cell-cultures and spheroids, in normoxic and hypoxic conditions. Cell proliferation, migration and key determinants of drug activity were evaluated by sulforhodamine-B-assay, wound-healing assay, PCR and LC-MS/MS.

Results: Lactate dehydrogenase A was significantly increased under hypoxic conditions $\left(1 \% \mathrm{O}_{2}\right)$, where the novel LDH-A inhibitors proved to be particularly effective (e.g., with IC 50 values of 0.9 vs $16.3 \mu \mathrm{M}$ for NHI-1 in LPC006 in hypoxia vs normoxia, respectively). These compounds induced apoptosis, affected invasiveness and spheroid-growth, reducing expression of metalloproteinases and cancer-stem-like-cells markers (CD133+). Their synergistic interaction with gemcitabine, with combination index values $<0.4$ in hypoxia, might also be attributed to modulation of gemcitabine metabolism, overcoming the reduced synthesis of phosphorylated metabolites.

Conclusion: Lactate dehydrogenase $\mathrm{A}$ is a viable target in PDAC, and novel LDH-A inhibitors display synergistic cytotoxic activity with gemcitabine, offering an innovative tool in hypoxic tumours.

Pancreatic ductal adenocarcinoma (PDAC) is the fourth leading cause of cancer-related death, with 5-year survival rate below 5\% (Siegel et al, 2012). The main reasons of this poor prognosis include invasive behaviour and multifactorial chemoresistance. These reasons might be at least in part explained by the key role of hypoxia in PDAC, as documented by its profound and characteristic avascular, hypodense appearance on contrast-enhanced computerised tomography, as well as by the low $\mathrm{pO}_{2}$ levels, of
0-5.3 $\mathrm{mm} \mathrm{Hg}$, whereas adjacent areas of normal pancreatic tissue have $\mathrm{pO}_{2}$ levels of $24-92.7 \mathrm{~mm} \mathrm{Hg}$ (Duffy et al, 2003). Hypoxia acts as a driving force in PDAC abnormal proliferation and metastatic behaviour, promoting the ingrowth of immature, architecturally deranged, and highly permeable blood vessels that facilitate the passage of tumour cells into the circulation (Koong et al, 2000; Harris, 2002; Chang et al, 2011). Furthermore, hypoxia has been associated with resistance of cancer cells to radiotherapy and

\footnotetext{
*Correspondence: Dr E Giovannetti; E-mail: e.giovannetti@vumc.nl or elisa.giovannetti@gmail.com

${ }^{5}$ These authors contributed equally to this work
}

Received 2 June 2013; revised 13 August 2013; accepted 8 October 2013; published online 31 October 2013 
chemotherapy (Verma et al, 2006; Whipple and Korc, 2008), and poor prognosis in PDAC patients (Hiraoka et al, 2010).

As illustrated in Figure $1 \mathrm{~A}$, a major consequence of intratumoral hypoxia is the metabolic switch from 'normal' oxidative phosphorylation to increased anaerobic glycolysis, which is required for tumour proliferation at low levels of oxygen and nutrients (Vasseur et al, 2010). A recent proteomic study identified several metabolic changes in PDAC cells compared with normal pancreatic duct cells, consistent with the 'Warburg effect' and with the reprogrammed energy metabolism processes emerging among the novel hallmarks of cancer (Hanahan and Weinberg, 2011; Zhou et al, 2011). As a result of these changes, cancer cells take up glucose and increase the concentration of lactate through lactate dehydrogenase A (LDH-A), directing glucose carbon away from the tricarboxylic acid cycle and fatty-acid synthesis (Metallo et al, 2011).

Lactate dehydrogenase $\mathrm{A}$ has been identified as a direct target of the c-myc and HER2/neu oncogenes (Fantin et al, 2006; Xie et al, 2009), as well as of hypoxia-inducible factor (HIF-1 $\alpha$ ) (Semenza, 2007; Le et al, 2010), which is a key transcription factor in hypoxic adaptation (Semenza, 2007; Le et al, 2010). Lactate dehydrogenase $\mathrm{A}$ is associated with the viability of tumour cells in hypoxia and overexpressed in metastatic cancer cells (Goldman et al, 1964; Granchi et al, 2011a). Several studies have illustrated the prognostic relevance of $\mathrm{LDH}$ in different tumour types including PDAC (Haas et al, 2013). More recently, a study on PDAC tissue and xenografts demonstrated that LDH-A is acetylated at lysine 5 (K5) and this acetylation, which inhibits LDH-A activity, is reduced in human PDAC, suggesting its role in PDAC initiation and as a potential new target (Zhao et al, 2013).

Therefore, we recently evaluated the activity of a series of novel $\mathrm{N}$-hydroxyindole-based (NHI) inhibitors, which displayed a good antiproliferative activity against different tumour cells including pancreatic cancer cells (Granchi et al, 2011b, c). As hypoxic cells are resistant to conventional anticancer therapies, such as the PDAC first-line standard agent gemcitabine, we also evaluated the molecular mechanisms underlying the pharmacological interaction of two of the most promising compounds among our new LDH-A inhibitors, in combination with gemcitabine. These studies were performed using both monolayer cell cultures, in normal and

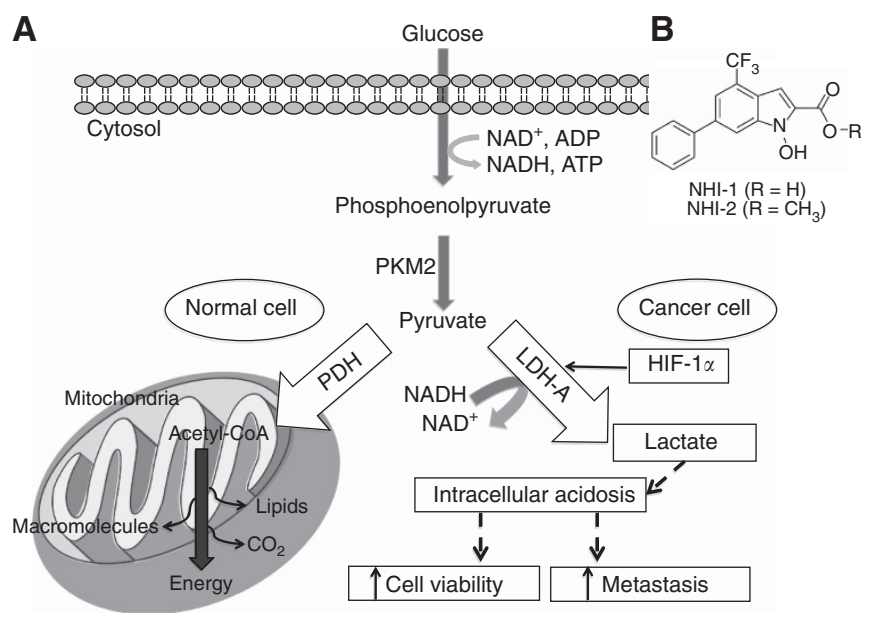

Figure 1. Metabolic pathways of aerobic/anaerobic glycolysis in normal/cancer cell. The glycolytic process and the two main metabolic pathways in which pyruvate is involved, depending on the presence of oxygen. In normal cells pyruvate undergoes the tricarboxylic acid (TCA) cycle, whereas in the hypoxic conditions of tumour cells, pyruvate is converted to lactate by LDH-A, which is induced by HIF-1 $\alpha$. Lactate can then promote cancer cell viability and metastasis. Abbreviations: HIF- $1 \alpha=$ hypoxia-inducible factor; LDH-A = lactate dehydrogenase $A$; $\mathrm{PDH}=$ pyruvate dehydrogenase; $\mathrm{PKM} 2=$ pyruvate kinase. hypoxic conditions, and PDAC cells growing as spheroids. Furthermore, we characterised several factors including cell-cycle perturbation, apoptosis induction, inhibition of cell migration, as well as modulation of the expression of several genes involved in the interaction of LDH-A inhibitors with gemcitabine.

\section{MATERIAL AND METHODS}

Drugs and chemicals. The LDH-A inhibitors NHI-1 and NHI-2 (Figure 1B) were synthesised at the Department of Pharmacy, University of Pisa, Italy, as described previously (Granchi et al, 2011a, 2013). Gemcitabine was provided by Eli Lilly Corporation (Indianapolis, IN, USA). The LDH-A inhibitors and gemcitabine were dissolved in DMSO and sterile water, respectively. The medium, foetal bovine serum (FBS), penicillin $\left(50 \mathrm{IU} \mathrm{ml}^{-1}\right)$ and streptomycin $\left(50 \mu \mathrm{g} \mathrm{ml}^{-1}\right)$ were from Gibco (Gaithersburg, MD, USA). All other chemicals were from Sigma (Zwijndrecht, the Netherlands).

Cell cultures. Seven PDAC cell lines, and the human immortalised pancreatic duct epithelial-like cells hTERT-HPNE were obtained from ATCC (Manassas, VA, USA), while seven primary PDAC cultures were isolated as described previously (Giovannetti et al, 2010). Cell lines were tested for their authentication by STR-PCR, performed by BaseClear (Leiden, the Netherlands).

The cells were cultured in RPMI-1640 supplemented with $10 \%$ heat-inactivated FBS, $1 \%$ penicillin/streptomycin. Cells were kept in a humidified atmosphere of $5 \% \mathrm{CO}_{2}$ and $95 \%$ air at $37^{\circ} \mathrm{C}$ and harvested with trypsin-EDTA. During the experiments in hypoxic conditions the cells were maintained at $\mathrm{O}_{2}$ tension of $1 \%, 5 \%$ (vol/vol) $\mathrm{CO}_{2}$, and $94 \%(\mathrm{vol} / \mathrm{vol}) \mathrm{N}_{2}$ at $37^{\circ} \mathrm{C}$, using a specific incubator IncuSafe Jacomex Glove Box (Labo Equipment Sanyo, Loughborough, UK).

Quantitative reverse-transcriptase PCR (qRT-PCR). RNAs were extracted using the QIAamp RNA MicroKit (Qiagen, Hilden, Germany), while cDNAs were synthesised using the DyNAmocDNA Synthesis Kit (Thermo Scientific, Vantaa, Finland). The qRT-PCRs were executed with specific TaqMan primers and probes, as described in the Supplementary Methods.

Western blot. In order to evaluate the modulation of LDH-A and HIF- $1 \alpha$ protein expression under normoxic and hypoxic conditions, PANC-1 and LPC006 were cultured for $72 \mathrm{~h}$ and western blotting was performed as described earlier (Avan et al, 2012). Briefly, $30 \mu \mathrm{g}$ of proteins was separated on a $10 \%$ SDSpolyacrylamide gel and transferred onto PVDF membrane (Immobilion-FL, Millipore, Billerica, MA, USA). The membrane was blocked with Rockland (Rockland Inc., Boyertown, PA, USA), and incubated overnight with rabbit anti-LDH-A (1:1000; Epitomics, Burlingame, CA, USA), rabbit anti-HIF- $1 \alpha$ ( $1: 250$; Cayman Chemical, Ann Arbor, MI, USA), and mouse anti- $\beta$-actin $(1: 10000$; Sigma). Additional studies evaluated the expression of E2F1, as described previously (Giovannetti et al, 2008).

Inhibition of LDH-A expression by siRNA anti-LDH-A. A specific siRNA against transcripts of LDH-A was purchased from Applied Biosystems (Foster City, CA, USA; s229664, AmbionSilencer). The sequences of sense and antisense strands of siRNA were 5'-GUA-UCU-UAA-UGA-AGG-ACU-Utt-' 3 and $5^{\prime}$-AAG-UUC-CUU-CAU-UAA-GAU-ACtg- ${ }^{\prime} 3$, respectively. Lipofectamine (Life Technologies, Bleiswijk, Netherlands) was used as transfection solution, as described in the Supplementary Methods.

LDH-A enzymatic activity. The inhibition of LDH-A enzymatic activity by NHI compounds, in cells treated with $10 \mu \mathrm{M}$ NHI-1 or NHI-2 under normoxic and hypoxic conditions, was performed 
by means of spectrophotometric measurement of oxidation of $\mathrm{NADH}$ via reduction of pyruvate to lactate, as described in the Supplementary Methods.

Growth inhibition studies. To evaluate the cell growth inhibitory effects of NHI compounds, gemcitabine, and their combinations under normoxic and hypoxic conditions, the sulforhodamine-B (SRB) assay was performed in PANC-1 and LPC006 cells. The cells were treated with NHI compounds at fixed concentration of $1 \mu \mathrm{M}$ (in hypoxia) or $10 \mu \mathrm{M}$ (in normoxia) simultaneously with gemcitabine $(1-500 \mathrm{nM})$. The rationale to investigate only the simultaneous and not sequential exposure was based on a recent study showing that the treatment of PDAC cells with the histone deacetylase inhibitor belinostat affected hypoxia signalling and interacted synergistically with gemcitabine using a simultaneous treatment (Chien et al, 2013). After $72 \mathrm{~h}$, plates were processed for the SRB assay (Giovannetti et al, 2011).

Analysis of cell cycle and measurement of cell death. In order to investigate the effect of NHI compounds on perturbation of cell cycle, PANC-1 and LPC006 cells were treated for $72 \mathrm{~h}$ with gemcitabine at $\mathrm{IC}_{50}$ values, 1 or $10 \mu \mathrm{M}$ NHI compounds, and their combination with gemcitabine, under hypoxic and normoxic conditions. Cells were stained by propidium iodide (PI) and cellcycle modulation was evaluated using a FACSCalibur (Becton Dickinson, San Jose, CA, USA).

To further evaluate S-phase entry we performed 5-bromo2 -deoxy-uridine (BrdU) incorporation assay. During the last hour of culture, cells were pulsed with $10 \mu \mathrm{M}$ BrdU. Then, they were incubated in denaturing solution $(2 \mathrm{M} \mathrm{HCl})$ for $20 \mathrm{~min}$, washed in $0.1 \mathrm{M}$ sodium borate, and stained with anti-BrdU antibody $(1: 50$; Harlan, Hillcrest, UK) in dilution buffer (PBS, 0.5\% Tween-20, $0.5 \%$ BSA) for $20 \mathrm{~min}$. Finally, the cells were counterstained with PI for flow cytometry analysis, using ModFit 3.2 (Verity-SoftwareHouse, Topsham, ME, USA).

$\mathrm{N}$-hydroxyindole-based inhibitors, gemcitabine and their combination were also characterised for their ability to induce cell death using the Annexin-V/PI assay, as described in the Supplementary Methods. Moreover, cells displaying apoptotic features were analysed by fluorescence microscopy with bisbenzimide staining, as described previously (Giovannetti et al, 2005). Cells treated as described above were washed with PBS and fixed in $4 \%$ buffered paraformaldehyde. Then cells were resuspended, incubated for 15 minutes in $8 \mu \mathrm{g} \mathrm{ml}^{-1}$ bisbenzimide $\mathrm{HCl}$ and examined by fluorescence microscopy (Leica Microsystems, Wetzlar, Germany). A total of 200 cells were counted and the percentage of cells displaying chromatin condensation and nuclear fragmentation relative to the total number of counted cells was calculated and reported as Apoptotic Index.

Evaluation of pharmacological interaction of NHI compounds with gemcitabine. The median-drug effect analysis method was employed for evaluating the interaction of NHI-1 and NHI-2 with gemcitabine (Bijnsdorp et al, 2011). The cell growth inhibition of the combination was compared with the cell growth inhibition of each drug alone using the combination index (CI), as described in the Supplementary Methods.

Activity of NHI compounds and gemcitabine in multicellular spheroids. PANC-1 and LPC006 spheroids were established seeding 10000 cells per $\mathrm{ml}$ in DMEM/F12 + GlutaMAX-I $(1: 1)$ with insulin-transferrin-selenium $(1: 1000$, Invitrogen), in ultralow attachment plates (Corning Incorporated, Corning, NY, USA). Spheroids were generated for 10-14 days, and then harvested for RNA isolation, immunofluorescence and growth inhibition studies.

After checking their growth rate and stability, PANC-1 and LPC006 spheroids were treated with $1 \mu \mathrm{M}$ of NHI compounds, $\mathrm{IC}_{50}$ values of gemcitabine and their combination for $72 \mathrm{~h}$. The cytotoxic effects were evaluated by measuring the size and number of spheroids with the Leica-DMI300B microscope (Leica Microsystems). Spheroid volume $(V)$ was calculated from the geometric mean of the perpendicular diameters $D=(D \max +D \min ) / 2,\left(V=(4 / 3) \times \pi(D / 2)^{3}\right)$.

LDH-A immunofluorescence. LDH-A expression was evaluated in spheroids seeded in eight-well chamber slides (Lab-Tek-II Chamber Slide System, Nalge-Nunc, Naperville, IL, USA), fixed in $4 \%$ paraformaldehyde/PBS, embedded in paraffin and sectioned. Seven-millimeter sections were stained for fluorescence detection using the anti-LDH-A antibody described above (at 1:200 dilution), probed with AlexaFluor488 (Life Technologies, Grand Island, NY, USA) secondary antibody. Sections were digitally imaged at $\times 40$, using a computerised high-resolution acquisition system (D-Sight, Menarini, Florence, Italy), equipped with DSight 2.1.0.

Migration and invasion assays. As previous findings demonstrated that hypoxia induced faster locomotion and a higher percentage of migrating PDAC cells (Salnikov et al, 2002), we evaluated whether NHI compounds might affect migration and invasion. For the migration assay the cells were plated at a density of $2 \times 10^{4}$ cells per well, and $24 \mathrm{~h}$ after incubation under hypoxic conditions, artificial wound tracks were created as described previously (Avan et al, 2012). The cells were exposed to $1 \mu \mathrm{M} \mathrm{NHI}$ compounds while combination experiments were performed by adding $1 \mu \mathrm{M}$ gemcitabine. Transwell chambers with polycarbonate membranes and $8 \mu \mathrm{m}$ pores were used for invasion assays as described in the Supplementary Methods.

Liquid chromatography-mass spectrometry (LC-MS/MS) measurement of phosphorylated gemcitabine. Analysis by LC-MS/MS was used to determine the total phosphorylated gemcitabine nucleosides, which were calculated from the difference before and after alkaline phosphatase treatment, in the Supplementary Methods.

Statistical analysis. All experiments were performed in triplicate and repeated at least twice. Data were expressed as mean values \pm s.e. and analysed by Student's $t$-test or ANOVA followed by the Tukey's multiple comparison test. The level of significance was $P<0.05$.

\section{RESULTS}

LDH-A is overexpressed in pancreatic cancer cells and is modulated by hypoxia. The mRNA expression of LDH-A and HIF- $1 \alpha$ was evaluated by quantitative RT-PCR in all the pancreatic cancer cells, as well as in the originator tissues of the primary tumour cell cultures. Lactate dehydrogenase A expression values differed among cells, ranging from 35.1 arbitrary unit (a.u.) in LPC006 cells to 138.9 a.u. in LPC028 cells (Figure 2A). The mean expression in the tumour cells (73.6 \pm 53.6 a.u.) was significantly higher than that in the normal hTERT-HPNE cells (1.2 \pm 0.2 a.u.; $P<0.01)$. Notably, LDH-A expression values in the seven primary tumour cells and in their laser-microdissected originator tumours showed a similar pattern and were highly correlated with Spearman analysis $\left(R^{2}=0.9, P<0.01\right)$.

PANC-1, LPC006, LPC028 and LPC167 cells were selected for further studies due to their levels of $L D H-A$ expression, which were representative of high, low, extremely high and median mRNA values, respectively.

After $72 \mathrm{~h}$ culture in $1 \% \mathrm{O}_{2}$ hypoxic conditions the expression of $L D H-A$ increased twofold in PANC-1, LPC006 and LPC067 cells, whereas we observed only a slightly increase of $L D H-A$ gene expression in LPC028 cells, as compared with normoxic conditions (Figure 2B). The expression of $L D H-A$ was further investigated at protein level in PANC-1 and LPC006 cells (Figure 2C). 
A

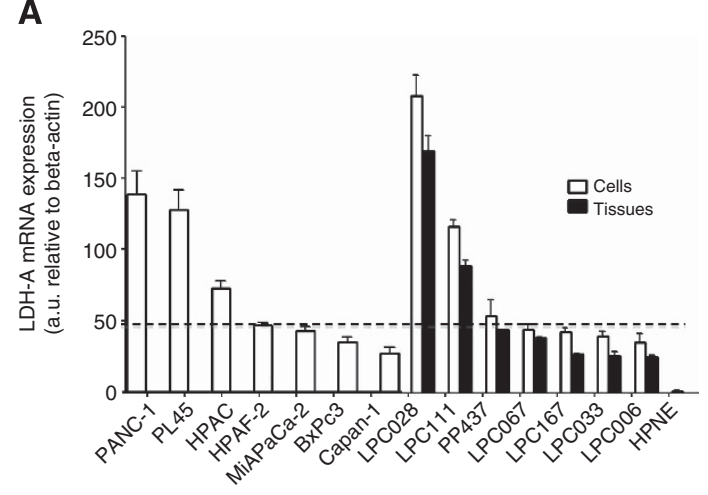

C

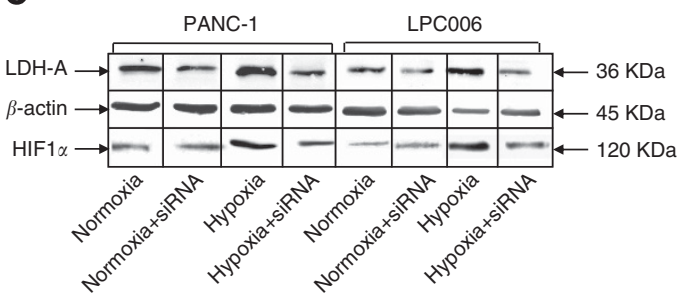

B

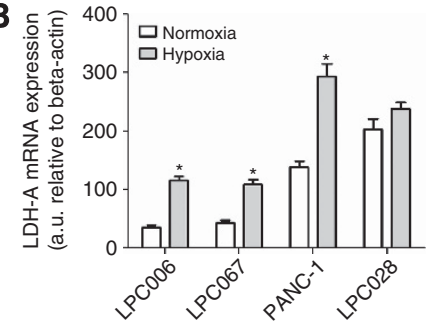

D PANC-1-siRNA-LDH PANC-1-SiRNA-CTR LPC006-SIRNA-LDH $\square$ ॠ* LPC006-SIRNA-CTR

PANC-1-SIRNA-LDH PANC-1-SIRNA-CTR LPC006-SIRNA-LDH LPC006-SIRNA-CTR
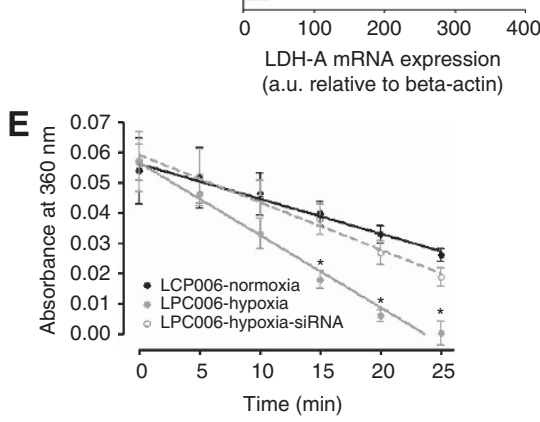

Figure 2. Expression and activity of LDH-A in pancreatic cancer cells. (A) LDH-A (black bars) mRNA expression in cell lines (white columns, 1-7, left to right), primary tumour cultures (white columns, 8-14, left to right), their originator tissues (black columns) and hTERT-HPNE normal pancreatic duct epithelial cells. (B) Modulation of the mRNA expression of LDH-A in LPC006, LPC067, PANC-1 and LPC028 cells after $24 \mathrm{~h}$ exposure to hypoxic conditions (grey bars); ${ }^{\star} P<0.05$ vs normoxic conditions for each cell type. (C) Modulation of LDH-A protein expression in PANC-1 and LPCO06 cells under hypoxic conditions, with and without transfection with $4 \mu \mathrm{M}$ siRNA anti-LDH-A. (D) Modulation of LDH-A mRNA expression in PANC-1 and LPC006 cells under hypoxic conditions (grey bars), with and without transfection with $4 \mu \mathrm{M}$ siRNA anti-LDH-A; ${ }^{\star} P<0.05$ vs cells transfected with control-siRNA (siRNA-CTR) in normoxic and hypoxic conditions for each cell type. (E) Modulation of LDH-A activity at protein level in LPCOO6 cells under hypoxic conditions, with and without transfection with $4 \mu \mathrm{M}$ siRNA anti-LDH-A. Columns, mean values obtained from three independent experiments. Bars, s.e.m.

In agreement with mRNA levels, LDH-A protein expression was higher in PANC-1 than in LPC006 cells. However, in both models LDH-A expression was increased in hypoxia, in parallel with the expression of HIF- $1 \alpha$. Conversely, treatment of the cells with $4 \mu \mathrm{M}$ siRNA anti-LDH-A caused a marked reduction of LDH-A expression at both mRNA and protein levels (Figure 2C and D), partially overcoming the induction by hypoxia in PANC-1 and LPC006 cells.

The modulation of LDH-A expression was reflected by similar changes in LDH-A activity, as determined by a specific spectrophotometric assay through oxidation of NADH. The basal LDH-A activity values of 0.0996 and $0.0624 \mu \mathrm{mol}$ lactate per min per mg protein in PANC-1 and LPC006 cells were increased in hypoxic conditions, whereas siRNA anti-LDH-A reverted the LDH-A activity to the levels detected in normoxia, as exemplified by the Figure 2E. In particular, in hypoxic conditions the amount of NADH that was consumed after 20 min increased by 71 and $82 \%$, in PANC-1 and LPC006 cells, respectively $(P<0.05)$.

NHI compounds target LDH-A activity. To determine their inhibition potencies and isoform selectivities NHI compounds were assayed on LDH-A and LDH-B purified isoforms, in competition experiments $v s$ both the cofactor (NADH) and the substrate (pyruvate), as described previously (Granchi et al, 2013). The IC50 values showed a similar selectivity, with a three- to fivefold LDH-A/LDH-B selectivity, associated to both NHI-1 and NHI-2, as reported in Supplementary Table 1.

Then, we evaluated the effects of the NHI compounds on $\mathrm{LDH}$ enzymatic activity of -A in PANC-1 and LPC006 cells treated with
$10 \mu \mathrm{M}$ NHI-1 or NHI-2, under normal and hypoxic conditions. These treatments significantly reduced the consumption rate of $\mathrm{NADH}$ in both PANC-1 and LPC006, mostly in cell homogenates collected in hypoxic condition, compared with that in untreated cells. NHI-1 was more effective than NHI-2 in both hypoxic and normoxic conditions. NHI-1 and NHI-2 reduced LDH activity in PANC-1 cells in hypoxic condition up to four- and twofold compared with controls. Similar effects were observed in the LPC006 cells (Figure 3A).

The cytotoxicity of NHI compounds is enhanced in hypoxic condition. Cell growth inhibitory effects of the NHI compounds were evaluated under normal and hypoxic conditions in PANC-1 and LPC006 cells. As detailed in Table 1, treatment of these PDAC cells with NHI-1 and NHI-2 showed a large variation, with the lowest growth inhibition rates in PANC-1 cells in normoxic conditions (e.g., $\mathrm{IC}_{50}$ values of 18.2 and $22.2 \mu \mathrm{M}$ after treatment with NHI-1 and NHI-2, respectively). The novel LDH-A inhibitors proved to be much more effective in hypoxia (e.g., $\mathrm{IC}_{50}$ values of 1.3 and $4.0 \mu \mathrm{M}$ for NHI-1 and NHI-2 in PANC-1 cells). LPC006 cells were also more sensitive in hypoxia, with $\mathrm{IC}_{50}$ values of 0.9 and 1.1 $\mu \mathrm{M}$, for NHI-1 and NHI-2, respectively. The key role of the modulation of LDH-A in the cytotoxicity of NHI compounds was further demonstrated by their reduced activity in PDAC cells exposed at nontoxic concentrations of a specific anti-LDH-AsiRNA, as shown in the Figure 3B.

Importantly, in the same PDAC models gemcitabine was highly cytotoxic, with $\mathrm{IC}_{50}$ values of 17.9 and $7.2 \mathrm{nM}$ in normoxia, 
A
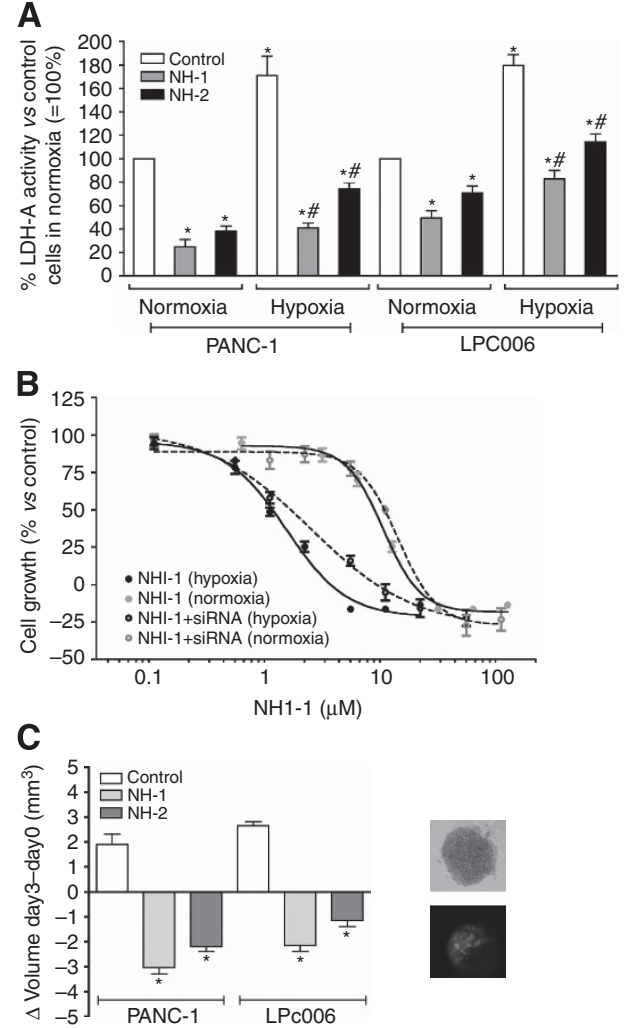

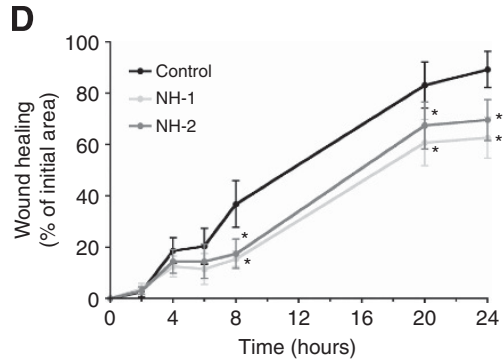

$\mathbf{E}$
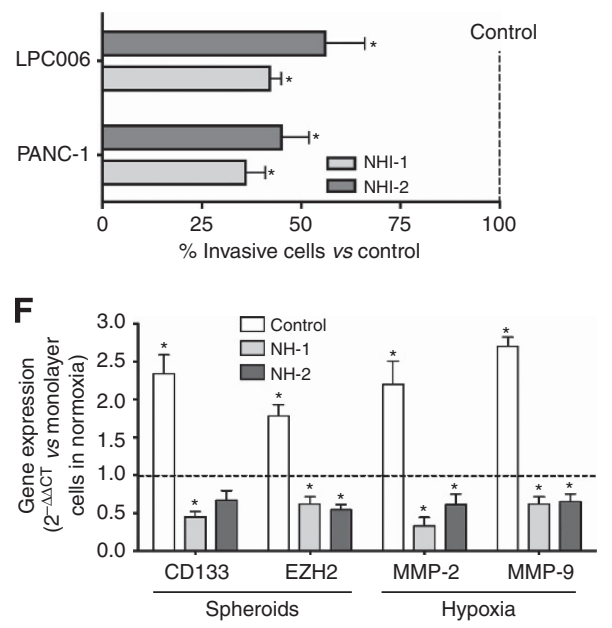

Figure 3. Effects of NHI compounds in PDAC cells. (A) Modulation of LDH-A activity by 72-h exposure to NHI compounds in PANC-1 and LPC006 cells in normoxia and hypoxia; ${ }^{\star} P<0.05$ vs control cells in normoxia, $\# P<0.05$ vs control cells in hypoxia. (B) Representative growth curves of LPC006 cells treated for $72 \mathrm{~h}$ with $\mathrm{NHI}-1$ under normoxic and hypoxic conditions, with and without transfection with $4 \mu \mathrm{M}$ siRNA anti-LDH-A; Points, mean values obtained from three independent experiments; bars, s.e.m. (C) Effect of $1 \mu \mathrm{M} \mathrm{NHI-1}$ or NHI-2 on the volumes of PDAC spheroids; ${ }^{*} P<0.05$ vs control cells; inset, representative pictures of LPC006 spheroids and immunofluorescence staining for LDH-A. (D) Results of wound-healing assay in LPC006 cells exposed to $1 \mu \mathrm{M} \mathrm{NHI-1}$ or $\mathrm{NHI}-2$, in hypoxia; ${ }^{\star} P<0.05$ vs control cells. (E) Results of invasion studies in LPC006 cells exposed for $24 \mathrm{~h}$ to $1 \mu \mathrm{M} \mathrm{NHI}-1$ or NHI-2, in hypoxia; ${ }^{\star} P<0.05$ vs control cells; (F) Modulation of CD133 and EZH2 expression in spheroids from LPC006 cells and modulation of MMP-2 and MMP-9 expression in LPC006 cells, exposed to $1 \mu \mathrm{M}$ NHI- 1 or NHI-2, for $72 \mathrm{~h}$, under hypoxia. Columns, mean values obtained from three independent experiments. Bars, s.e.m. ${ }^{\star} P<0.05$ vs cells growing as monolayers in normoxic conditions.

Table 1. Cell growth inhibitory effects and pharmacological interaction of $\mathrm{NHI}$ compounds and gemcitabine, in normoxic and hypoxic conditions in PANC- 1 and LPCO06 cells

\begin{tabular}{|l|c|c|c|c|c|c|}
\hline & & $I^{50}(\mu \mathrm{M})$ & $I_{50}(\mu \mathrm{M})$ & $I_{50}$ & Combination index (CI) & \\
\hline Cells & Condition/Drug & NHI-1 & NHI-2 & Gemcitabine & NHI-1 + Gemcitabine & Pharmacological interaction results \\
\hline PANC-1 & Normoxia & $18.2 \pm 3.7$ & $22.2 \pm 2.4$ & $17.9 \pm 1.3 \mathrm{nM}$ & $0.45 \pm 0.12$ & Synergism \\
& Hypoxia & $1.3 \pm 0.2$ & $4.0 \pm 0.06$ & $0.20 \pm 0.04 \mu \mathrm{M}$ & $0.14 \pm 0.06$ & Strong synergism \\
\hline LPC006 & Normoxia & $16.3 \pm 2.5$ & $17.8 \pm 0.1$ & $7.3 \pm 1.3 \mathrm{nM}$ & $0.79 \pm 0.18$ & Slight synergism \\
& Hypoxia & $0.9 \pm 0.4$ & $1.1 \pm 0.5$ & $0.15 \pm 0.03 \mu \mathrm{M}$ & $0.29 \pm 0.53$ & Strong synergism \\
\hline \multirow{2}{*}{ IC $_{50}$ value: $50 \%$ growth inhibitory concentration. } \\
\hline
\end{tabular}

whereas $\mathrm{IC}_{50}$ values were increased up to 11 - and 20 -fold under hypoxia, in PANC-1 and LPC006 cells, respectively.

NHI compounds reduce the size of PDAC spheroids and downregulate $C D 133$ and $E Z H 2$ expression. Previous studies showed that three-dimensional (3D) culture models are generally more chemo- and radio-resistant than two-dimensional monolayer cell cultures, supporting the use of these models for drug testing (Padrón et al, 2000; Longati et al, 2013). Moreover, the use of serum-free cancer-stem cell medium should select a population of
PDAC cells harbouring CSCs characteristics (Avan et al, 2013), as well as cells with higher stability of HIF1-alpha and increased lactate accumulation (Longati et al, 2013).

Thus, in order to determine whether NHI compounds would be active in $3 \mathrm{D}$ systems, we tested these drugs in spheroids of PANC-1 and LPC006 cells that were below $500 \mu \mathrm{m}$ in diameter. These growing spheroids showed a high expression of LDH-A, as detected with immunofluorescence (inset in the Figure $3 \mathrm{C}$ ), and were exposed to NHI-1 and NHI-2 for $72 \mathrm{~h}$. Notably, both NHI compounds remarkably increased the disintegration of these 
spheroids, which were significantly reduced in size compared with the untreated spheroids (Figure 3C). Concomitant with these changes, treatment with NHI compounds decreased the mRNA expression levels of the CSC markers CD133 and EZH2 (Figure 3F), which were increased in the spheroids compared with the monolayer cultures (data not shown).

NHI compounds inhibit cell migration and downregulate expression of metalloproteinases. To investigate the effects of these NHI-based LDH-A inhibitors on migratory behaviour, we performed a scratch motility assay in PANC-1 and LPC006 cell lines in hypoxic conditions, using concentrations that were insufficient to inhibit cell proliferation in only $24 \mathrm{~h}$. LPC006 showed a significant reduction of migration starting after $8 \mathrm{~h}$ ( $\sim 20 \%$ compared with control), as illustrated in Figure 3D. Similarly, the percentages of cellular migration in PANC-1 after 8, 20 and $24 \mathrm{~h}$ exposure to both NHI compounds were $\sim 20 \%, 60 \%$, and $70 \%$, respectively. The cells treated with NHI-1 and NHI-2 showed also significantly less invasive potential (Figure $3 \mathrm{E}$ ).

The above results led us to hypothesise that LDH-A has a key role in cancer cell migration and invasion. This may be attributed to modulation of metalloproteinases expression. Therefore, we investigated the expression of MMP-2 and MMP-9, showing a significant reduction after treatment with NHI compounds (Figure 3F).

NHI compounds synergistically enhance the antiproliferative activity of gemcitabine. Combination studies showed that both NHI-1 and NHI-2 enhanced the antiproliferative activity of gemcitabine, under normoxia and hypoxia, in both PANC-1 and LPC006 cells. In particular, the $\mathrm{IC}_{50}$ values of gemcitabine were reduced by about fourfold after exposure to NHI-1 in hypoxia in LPC006 cells (Figure 4A). Combination index values for all the combinations and conditions are reported in Table 1. These CIs showed slight-to-moderate synergism in normoxic conditions, and strong synergism under hypoxia, in both PANC-1 and LPC006 cells.

Moreover, these combinations remarkably increased the disintegration of multicellular spheroids, which were significantly reduced in size compared with the spheroids exposed to gemcitabine alone in both our two PDAC cellular models (Figure 4B). Notably, the combinations counteracted the increase of CD133 and EZH2 mRNA levels induced by gemcitabine alone ( +57 and $85 \%$ in PANC- 1 , and +39 and $48 \%$ in LPC006 cells, respectively), (Figure $4 \mathrm{C}$ ). In order to evaluate the mechanisms underlying this synergistic interaction, several biochemical analyses were performed, as detailed below.

NHI compounds overcome the reduced synthesis of gemcitabine nucleotides in hypoxia and increase $d C K$ expression through E2F1 modulation. To investigate the molecular mechanisms underlying the reduced activity of gemcitabine in hypoxic conditions, we measured gemcitabine nucleotides in LPC006 cells treated with gemcitabine in hypoxic conditions for $24 \mathrm{~h}$, showing a significantly decreased cellular accumulation compared with cells in normoxic conditions (Figure 4D). These changes in the pools of these gemcitabine nucleotides were associated with a significant decrease in the mRNA expression levels of $d C K$ (Figure $4 \mathrm{E}$ ). Conversely, no changes were observed for $h E N T 1$ expression levels (data not shown). NHI compounds partially increased gemcitabine nucleotides levels, as well as $d C K$ expression. Of note, the combination of gemcitabine with both NHI-1 and NHI-2 determined a significant increase in $d C K$ expression, suggesting its potential role in the synergistic interaction. Finally, we studied the protein levels of E2F1, as reported in the blots in Figure 4E, showing a decrease in hypoxic conditions, whereas the NHI compounds determined a significant enhancement of E2F1 expression.
The combinations of NHI compounds with gemcitabine affect cell cycle and induce apoptosis. As reported in Table 2, perturbation in the cell cycle of PANC-1 and LPC006 cells treated with NHI compounds, gemcitabine and their combination was investigated in normal and hypoxic conditions.

NHI compounds significantly affect cell cycle distribution by decreasing PANC-1 cells in $\mathrm{G}_{1}$ phase, particularly in hypoxic conditions, whereas gemcitabine did not change cell cycle distribution in hypoxia but increased the percentage of normoxic cells in $\mathrm{G}_{2}-\mathrm{M}(P<0.05)$. The combination significantly decreased the cells in $G_{1}$ phase, while increasing the cells in $S$ phase both in normoxia and hypoxia (e.g., from $13.3 \%$ in control to $35.5 \%$ in cells treated with NHI-1 and gemcitabine, in hypoxic condition). Similar perturbations of cell cycle were observed in the LPC006 cells, suggesting that NHI compounds might overcome the block in the $G_{1}-S$ boundary induced by hypoxia, while the increase in $S$ phase might favour gemcitabine activity (Supplementary Figure 1A).

Annexin-V analysis demonstrated that drug treatments significantly enhanced cell death and apoptosis compared with the control. LPC006 cells treated with combination exhibited the highest apoptosis induction (Supplementary Figure 1B). Similar results were observed with fluorescence microscopy showing that PDAC cells exposed to the NHI compounds, gemcitabine and their combination presented the typical apoptotic morphology with cell shrinkage, nuclear condensation and fragmentation, and rupture of cells into debris (inset in Figure 4F). In all cell lines, $20-25 \%$ of apoptotic cells were observed after gemcitabine treatment, whereas combinations of gemcitabine with NHI compounds in hypoxia was associated with a higher percentage $(>40 \%)$ of apoptotic cells, as illustrated in Figure 4D for the LPC006 cells. Statistics revealed that drug combination significantly increased the apoptotic index, compared with both control cells and gemcitabine-treated cells. However, treatment of the cells with $4 \mu \mathrm{M}$ siRNA anti-LDH-A reduced the pro-apoptotic effects of NHI compounds, alone and in combination with gemcitabine (Supplementary Figure 1C).

The combinations of NHI compounds with gemcitabine inhibit cell migration and invasion. LPC006 cells treated with the combinations of NHI compounds and gemcitabine in hypoxic conditions had significantly decreased wound healing, with percentages of cellular migration after $8 \mathrm{~h}$ reduced to $30 \%$ vs untreated cells $(P<0.05)$, whereas gemcitabine alone did not affect cell migration. Similar results were observed in the experiments on cell invasion (Supplementary Figure 2). Conversely, treatment of the cells with $4 \mu \mathrm{M}$ siRNA anti-LDH-A reduced the anti-invasive effects of NHI compounds, alone and in combination with gemcitabine.

\section{DISCUSSION}

This is the first study evaluating the pharmacological interaction of novel LDH inhibitors with gemcitabine in pancreatic cancer. These compounds were effective against PDAC cells under hypoxic condition and their combination with gemcitabine was synergistic in PDAC cells under normoxic and hypoxic conditions. This synergistic effect was associated with increase in apoptosis and inhibition of cell migration.

These results are particularly interesting, as PDACs are characterised by a dense desmoplastic stroma and a sparse vascularisation that limit oxygen/nutrients availability. This architecture induces severe hypoxic stress to tumour cells, which become resistant to chemotherapy and are able to increase their invasive and metastatic potential (Brown and Giaccia, 1998; Le et al, 2004). The ability of cancer cells to survive under hypoxic conditions result from their ability to reprogram canonical 
A
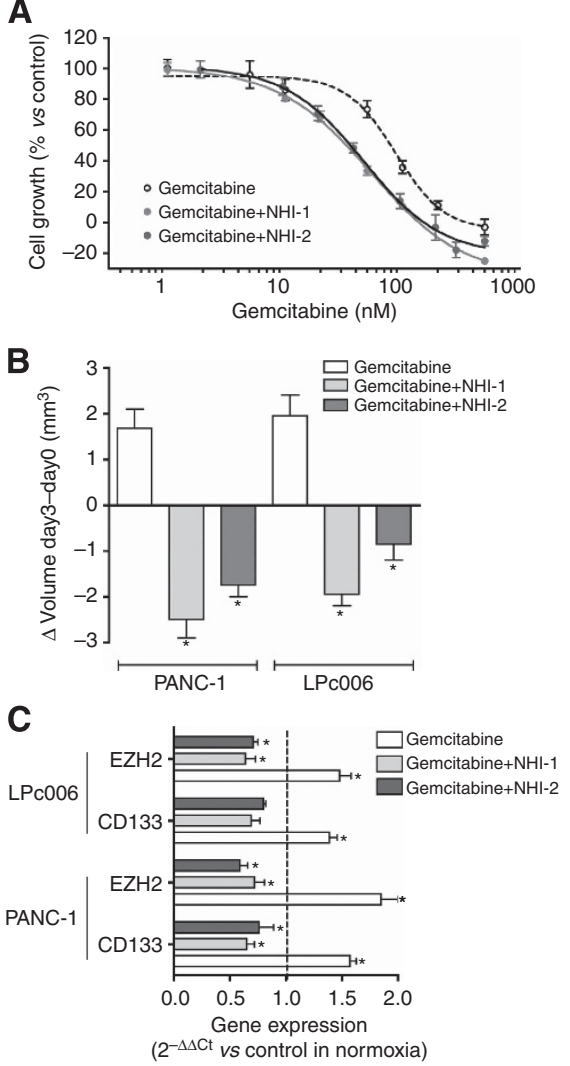

D

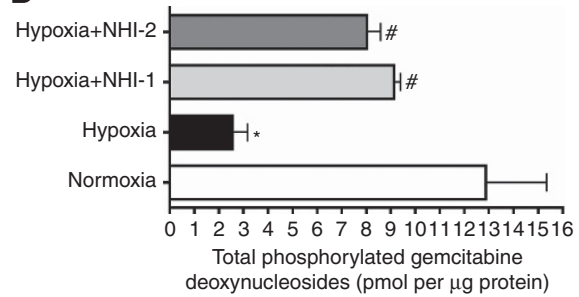

$\mathbf{E}$
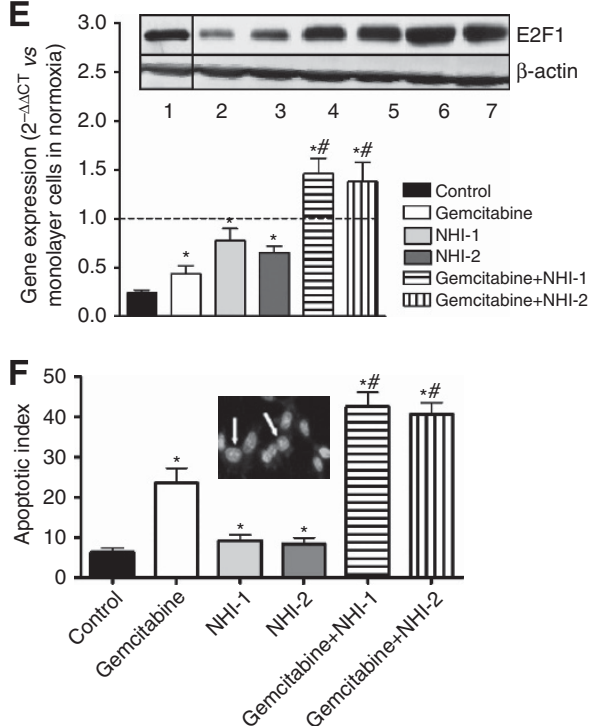

Figure 4. Antiproliferative and pro-apoptotic effects of NHI compounds. (A) Representative growth curves of LPC006 cells treated with gemcitabine, and the combination of gemcitabine with $1 \mu \mathrm{M} \mathrm{NHI}-1$ or $\mathrm{NHI}-2$, in hypoxic conditions; points, mean values obtained from three independent experiments; bars, s.e.m. (B) Effect of gemcitabine, at IC $\mathrm{C}_{50}$, and its combination with $1 \mu \mathrm{M}$ NHI-1 or NHI-2 on the volumes of PDAC spheroids; ${ }^{*} P<0.05$ vs controls. (C) Modulation of CD133 and EZH2 expression in spheroids from LPC006 and PANC-1 cells exposed to gemcitabine, at $\mathrm{IC}_{50}$, and its combination with $1 \mu \mathrm{M} \mathrm{NHI}-1$ or NHI-2. Columns, mean values obtained from three independent experiments. Bars, s.e.m. ${ }^{*} P<0.05$ vs cells growing as monolayers in normoxic conditions. (D) Modulation of total phosphorylated gemcitabine deoxynucleosides in LPC006 cells in hypoxic conditions with and without exposure to NHI compounds; ${ }^{*} P<0.05$ vs control, ${ }^{\#} P<0.05$ vs control cells in hypoxia. (E) Modulation of E2F1 expression (representative blots: lane 1, control in normoxia; lane 2, control in hypoxia; lane 3, gemcitabine; lane 4, NHI-1; lane 5 NHI-2; lane 6, NHI-1 + gemcitabine; NHI-2 + gemcitabine) and of dCK expression in LPC006 cells, exposed to gemcitabine at $\mathrm{IC}_{50}, 1 \mu \mathrm{M} \mathrm{NHI}-1$ or $\mathrm{NHI}-2$, and their combinations, for $72 \mathrm{~h}$, under hypoxia. Columns, mean values obtained from three independent experiments. Bars, s.e.m. ${ }^{\star} P<0.05$ vs cells growing as monolayers in normoxic conditions; ${ }^{\#} P<0.05$ vs cells treated with gemcitabine; (F) Induction of apoptosis, as detected by bisbenzimide staining in LPC006 cells exposed to gemcitabine, $1 \mu \mathrm{M} \mathrm{NHI-1} \mathrm{or} \mathrm{NHI-2,} \mathrm{and}$ their combinations, in hypoxic conditions. Columns, mean values obtained from three independent experiments. Bars, s.e.m. ${ }^{\star} P<0.05$ vs control, ${ }^{\#} P<0.05$ vs cells treated with gemcitabine; inset, representative picture of cells with apoptotic features (white arrows).

biochemical pathways in order to provide sufficient energy (Vasseur et al, 2010; Feig et al, 2012). A recent study by Zhou et al (2011) showed several metabolic changes in proteomes of PDAC cells compared with normal pancreatic duct cells. As a result of these metabolic changes, cancer cells tend to take up more glucose and generate lactate through LDH-A (Metallo et al, 2011).

$\mathrm{LDH}$ is an oxidoreductase, which catalyses the conversion of pyruvate to lactate by using a NADH/NAD ${ }^{+}$cofactor. Human $\mathrm{LDH}$ is a tetrameric enzyme that is composed of three different monomeric subunits: LDH-A, LDH-B and LDH-C. The C subunit is only part of homotetrameric enzyme, $\mathrm{LDH}-\mathrm{C}$, which has an important role in male fertility (Goldberg, 1985), while the A and B subunits are mainly present in skeleton muscles/liver and heart, respectively (Brooks et al, 1999; Granchi et al, 2011a, b, c). In agreement with our results, showing a parallel modulation in hypoxic conditions, LDH-A upregulation was associated with overexpression of the pleiotropic hypoxic transcription factor HIF$1 \alpha$ (Koukourakis et al, 2006; Kolev et al, 2008). LDH-A is overexpressed in hypoxic carcinomas as well as metastatic cancer cells, and has been correlated to tumour vitality (Goldman et al, 1964; Koukourakis et al, 2005). The lactate produced by tumour cells creates acidic conditions that favour tumour invasion (Swietach et al, 2007), and suppresses anticancer immune effectors (Fischer et al, 2007). Moreover, lactate can be taken up by stromal cells to regenerate pyruvate that either can be extruded to refuel the cancer cell or can be used for OXPHOS (Koukourakis et al, 2006), which ensures the cell's antioxidant defences against chemotherapeutic agents (Gatenby and Gillies, 2004). This arrangement generates an ecosystem in which cancer and stromal cells use complementary metabolic pathways, recycling products of anaerobic metabolism to sustain cancer cell survival and invasion.

Against this background, LDH-A has been identified as an attractive target for therapies tackling tumour initiation, maintenance and progression through modulation of cancer energy metabolism. Recent studies showed that knockdown of LDH-A by shRNA stimulated mitochondrial oxygen-dependent oxidative phosphorylation, decreased cell proliferation under hypoxia, suppressed tumorigenicity and enhanced chemosensitivity (Zhou et al, 2010; Metallo et al, 2011; Zhou et al, 2011). Furthermore, reduction of LDH-A by siRNA or its inhibition by small-molecule FX11 inhibited the progression of sizable human lymphoma and pancreatic cancer xenografts (Le et al, 2010). The inhibition of 


\begin{tabular}{|c|c|c|c|c|}
\hline Cells & Treatments & G0/G1 Phase (\%) & S Phase (\%) & G2/M Phase (\%) \\
\hline \multirow[t]{2}{*}{ PANC-1 normoxia } & Control & $50.5 \pm 1.4$ & $26.5 \pm 1.1$ & $23.0 \pm 1.0$ \\
\hline & $\begin{array}{l}\text { Gemcitabine } \\
\text { NHI-1 } \\
\text { NHI-1 + Gemcitabine } \\
\text { NHI-2 } \\
\text { NHI-2 + Gemcitabine }\end{array}$ & $\begin{array}{l}43.5 \pm 2.5 \\
38.9 \pm 19 \\
35.9 \pm 3.6 \\
37.4 \pm 3.1 \\
36.9 \pm 2.8\end{array}$ & $\begin{array}{l}29.8 \pm 2.6 \\
33.9 \pm 0.8 \\
34.6 \pm 2.1 \\
32.0 \pm 1.7 \\
33.3 \pm 1.6\end{array}$ & $\begin{array}{l}26.7 \pm 3.4 \\
27.2 \pm 2.0 \\
29.6 \pm 2.2 \\
30.6 \pm 2.3 \\
29.8 \pm 2.1\end{array}$ \\
\hline \multirow[t]{2}{*}{ PANC-1 hypoxia } & Control & $62.4 \pm 3.2$ & $13.3 \pm 0.4$ & $24.3 \pm 2.4$ \\
\hline & $\begin{array}{l}\text { Gemcitabine } \\
\mathrm{NHI}-1 \\
\mathrm{NHI}-1+\text { Gemcitabine } \\
\mathrm{NHI}-2 \\
\mathrm{NHI}-2 \text { + Gemcitabine }\end{array}$ & $\begin{array}{l}59.9 \pm 4.1 \\
43.1 \pm 2.2 \\
38.2 \pm 1.8 \\
40.1 \pm 1.9 \\
39.5 \pm 1.3\end{array}$ & $\begin{array}{l}14.5 \pm 1.2 \\
33.9 \pm 1.3 \\
35.5 \pm 1.7 \\
32.9 \pm 2.5 \\
34.3 \pm 1.2\end{array}$ & $\begin{array}{l}26.2 \pm 1.7 \\
22.9 \pm 2.5 \\
26.3 \pm 1.7 \\
26.9 \pm 2.1 \\
26.2 \pm 1.1\end{array}$ \\
\hline \multirow[t]{2}{*}{ LPC006 normoxia } & Control & $55.4 \pm 2.3$ & $22.8 \pm 1.6$ & $21.8 \pm 0.9$ \\
\hline & $\begin{array}{l}\text { Gemcitabine } \\
\mathrm{NHI}-1 \\
\mathrm{NHI}-1+\text { Gemcitabine } \\
\mathrm{NHI}-2 \\
\mathrm{NHI}-2 \text { + Gemcitabine }\end{array}$ & $\begin{array}{l}38.3 \pm 1.5 \\
36.4 \pm 2.7 \\
35.9 \pm 1.5 \\
37.8 \pm 3.2 \\
35.9 \pm 1.9\end{array}$ & $\begin{array}{l}30.1 \pm 1.1 \\
35.2 \pm 2.4 \\
34.6 \pm 1.2 \\
34.2 \pm 1.8 \\
34.6 \pm 1.9\end{array}$ & $\begin{array}{l}31.6 \pm 2.4 \\
28.4 \pm 1.6 \\
29.6 \pm 8.5 \\
28.0 \pm 3.3 \\
29.6 \pm 2.4\end{array}$ \\
\hline \multirow[t]{2}{*}{ LPC006 hypoxia } & Control & $63.5 \pm 3.8$ & $17.2 \pm 2.0$ & $19.3 \pm 1.97$ \\
\hline & $\begin{array}{l}\text { Gemcitabine } \\
\mathrm{NHI}-1 \\
\mathrm{NHI}-1+\text { Gemcitabine } \\
\mathrm{NHI}-2 \\
\mathrm{NHI}-2 \text { + Gemcitabine }\end{array}$ & $\begin{array}{l}61.1 \pm 2.8 \\
43.6 \pm 1.4 \\
39.8 \pm 3.9 \\
44.5 \pm 3.1 \\
40.9 \pm 3.4\end{array}$ & $\begin{array}{l}18.5 \pm 0.9 \\
33.7 \pm 1.7 \\
36.7 \pm 1.8 \\
31.9 \pm 2.1 \\
35.5 \pm 3.2\end{array}$ & $\begin{array}{l}20.4 \pm 2.1 \\
22.7 \pm 1.9 \\
23.5 \pm 2.2 \\
23.6 \pm 2.2 \\
23.6 \pm 1.2\end{array}$ \\
\hline
\end{tabular}

LDH-A can be achieved without influencing the energetic balance of normal tissues (Manerba et al, 2012), and has not been shown to raise major side effects, in agreement with the observation that hereditary LDH-A deficiency does not provoke any symptoms under ordinary circumstances in humans (Kanno et al, 1988).

All these findings suggest that LDH-A is a promising and safe target, and novel LDH inhibitors represent an innovative, selective and also potentially nontoxic strategy of interfering with hypoxic cancer growth. Recently, we developed a new class of $\mathrm{N}$ hydroxyindole-based inhibitors of LDH-A (NHIs), which proved to inhibit the growth of different tumour cells, including PDAC cells, especially in hypoxic conditions (Granchi et al, 2011a, c). The relatively weak inhibition of $\mathrm{LDH}$ enzymatic activity compared with the in vitro effects on cells might at least in part be explained by the key role of LDH-A in the metabolism of cancer hypoxic cells. However, further studies on potential off-targets effects of our drugs are warranted.

Furthermore, monotherapy activity is not a realistic expectation for hypoxia-selective agents because hypoxic cells represent only a subpopulation (although a critically important one) in most tumours and that these agents should have peculiar requirements such as long residence time in tumours (to exploit fluctuating hypoxia) or efficient, long-range bystander killing (Wilson and Hay, 2011). On the other hand, inhibition of molecular targets in hypoxic cells should offer a more benign toxicity profile, which is distinctly different from that of cytotoxic therapy, and therefore have greater opportunity for combination with current standards of care. Therefore, the study of compatibility with existing therapy is fundamentally important for the clinical translation of these new drugs, and, to our knowledge, this is the first study evaluating the pharmacological interaction of $\mathrm{LDH}$ inhibitors with gemcitabine in PDAC cells.

The expression of LDH-A was detectable in all our PDAC cells, including seven primary tumour cell cultures, in their first passages, where the levels of LDH-A mRNA were comparable to their originator tumours, suggesting that these cells represent optimal preclinical models for our pharmacological studies. Conversely, LDH-A levels were significantly lower in the normal pancreatic ductal cells HPNE, in agreement with earlier data on normal pancreatic specimens (Zhao et al, 2013).

The expression of LDH-A was significantly increased under hypoxic conditions, both at mRNA and protein levels. Moreover, this upregulation of LDH-A expression was associated with increased LDH-A activity, as detected by an enzymatic assay, which on the contrary was reduced by a specific siRNA anti-LDHA, supporting the use of this method to test the effects of the NHI compounds. These compounds were able to reach their target also in vitro, as demonstrated by the inhibition of PDAC cell proliferation, especially under hypoxic conditions.

Conversely, hypoxia dramatically affected gemcitabine activity, reducing the synthesis of active gemcitabine deoxynucleotides, possibly also through downregulation of the rate-limiting enzyme $d C K$.

These results are in agreement with several studies showing that hypoxia compromised the cytotoxic effect of gemcitabine in PDAC cells (Yokoi and Fidler, 2004; Zhang et al, 2005), but other studies reported no significant effects of gemcitabine cytotoxicity in lung cancer cells (Lam et al, 2009; Wouters et al, 2011), suggesting a cell-dependency of this phenomenon.

The combination of oxaliplatin, irinotecan, fluorouracil, and leucovorin as well as abraxane plus gemcitabine have better antitumor activity compared with gemcitabine alone (Heinemann et al, 2012). However, these therapeutic strategies are associated with increased toxicity, and further studies are still needed to evaluate novel strategies to improve gemcitabine activity against PDAC.

In the present study we demonstrated that NHI compounds synergistically enhanced the activity of gemcitabine in two 
representative PDAC models, PANC-1 cells and the primary tumour cell culture LPC006. The synergistic interaction against cell proliferation was associated with a significant increase in apoptosis induction. Prolonged or recurrent tumour hypoxia selects for cancer cells with increased survival signalling and loss of apoptotic potential (Graeber et al, 1996). Therefore, the development of agents that target hypoxic cells and increase apoptosis represents an important approach for the rational design of new effective combinations. Moreover, both NHI-1 and NHI-2 overcome the arrest of the cell cycle in the G1 phase, as observed in hypoxic cells compared with cells growing in normoxia. The increase of gemcitabine activity in the combination with NHI compounds may be the result of this modulation of the cell cycle, with an increased number of cells in the $\mathrm{S}$ and $\mathrm{G}_{2}-\mathrm{M}$ phase, potentially facilitating the incorporation of gemcitabine metabolite $2^{\prime}, 2^{\prime}$ difluorodeoxycytidine triphosphate into DNA, and apoptosis induction (Elnaggar et al, 2012).

Moreover, our findings show that the synergistic interaction of NHI compounds with gemcitabine is also mediated by other mechanisms, which reduced the aggressiveness of PDAC and enhanced the sensitivity to gemcitabine.

As one of the major hallmarks of PDAC is its early dissemination, and hypoxia promotes invasion and metastasis in PDAC (Salnikov et al, 2002), we evaluated whether NHI compounds might affect PDAC cell migration/invasion. In agreement with previous studies, showing that shRNA or siRNA mediated knockdown of LDH-A, and attenuated MDA-MB-435 and glioma cells migration (Baumann et al, 2009; Arseneault et al, 2013), we observed that inhibition of LDH by NHI compounds and their combination with gemcitabine significantly reduced wound healing. These anti-migratory effects were accompanied by downregulation of MMPs, as reported previously (Baumann et al, 2009).

Notably, recent data demonstrate that hypoxia is also involved in generating cells with properties of cancer stem cells, which might have a key role in PDAC chemoresistance (Hashimoto et al, 2011). Therefore, we investigated whether NHI compounds affect the volume of PDAC spheroids growing in serum-free stem-cell medium. Gemcitabine only slightly reduced the volume of these spheroids, possibly by affecting some remaining bulk tumour cells, but it increased the expression of the CSC marker CD133. This suggests that exposure to gemcitabine might select a population of more aggressive cells, as observed previously (Avan et al, 2012). Conversely, the NHI compounds were able to effectively deplete the most aggressive subpopulation of PDAC cells, as suggested by the significant reduction of both spheroids and CD133 expression.

Finally, the present study also showed that NHI compounds interfered with $d C K$, which is a pivotal determinant for the cytotoxic activity of gemcitabine (Elnaggar et al, 2012). In hypoxic conditions we observed a significant reduction of gemcitabine active metabolites and a downregulation of $d C K$, whereas treatment with NHI compounds was associated with a rescue of their levels, which might at least in part explain the synergistic interaction with gemcitabine. As the promoter of $d C K$ has a binding site for E2F1 (Chen et al, 1995), and a recent study showed that HIF- $2 \alpha$ inhibited the expression of the transcription factor dimerisation partner-3, which in turn inhibited E2F1 (Sun et al, 2013), we can hypothesise that the reduced levels of $d C K$ were determined by modulation of E2F1 in hypoxia. Conversely, E2F1 levels were increased after exposure to NHI compounds, potentially favouring both gemcitabine activity and induction of S-phase entry. Indeed E2F1 is one of the main regulators during the G1/S transition. As both E2F and MYC families are important regulators of cell cycle, and $\mathrm{LDH}$ is a main target of $\mathrm{MYC}$ (Patel et al, 2004), our LDH inhibitors might modulate E2F1 expression through feedback mechanisms that warrant further studies.
In conclusion, NHI inhibitors of LDH-A emerged as very promising anticancer agents, by attacking key mechanisms involved in the proliferation, cell-cycle control, apoptosis, stemness, and migration properties of PDAC cells, especially under hypoxic conditions. Moreover, the favourable modulation of $d C K$ makes these compounds excellent candidates for combination with gemcitabine. These extensive in vitro studies are essential for the judicious selection of the best antihypoxic cell therapies and combinations to be tested in future in vivo tumour models, and may have critical implications for the rational development of innovative regimens including $\mathrm{LDH}-\mathrm{A}$ inhibitors and gemcitabine to improve the treatment of PDAC.

\section{ACKNOWLEDGEMENTS}

We would like to thank Dr E Paolicchi (University of Pisa) and Dr V Galla' (University of Bologna) for the help on initial experiments with spheroids and invasion; Professor A Griffioen (Angiogenesis group, Department Medical Oncology, VUmc, Amsterdam VUmc, Amsterdam) for the migration station used to perform woundhealing assays, and Dr P Koolwijk (Department of Physiology, VUmc, Amsterdam, The Netherlands) for the hypoxia incubator used to perform experiments in hypoxic conditions. This work was supported by grants from EORTC-PAMM (Godefridus J Peters, Elisa Giovannetti, Filippo Minutolo), CCA-VICI foundation (grant no 2012-5-07, Amir Avan, Godefridus J Peters, Elisa Giovannetti), Netherlands Organization for Scientific Research (NWO, Veni grant, Elisa Giovannetti), AIRC-Marie Curie (International Fellowship, Elisa Giovannetti); Istituto Toscano Tumori grant (Ugo Boggi, Niccola Funel, Elisa Giovannetti), European Union FP7-REGPOT-2012CT2012-31637-IMBRAIN (Leticia G Leon, Elisa Giovannetti, Godefridus J. Peters), European Union Seventh Framework Programme (FP7/2007-2013) under grant agreement no PIIF-GA-2011-299026 (Filippo Minutolo, Reshma Rani).

CONFLICT OF INTEREST

The authors declare no conflict of interest.

\section{REFERENCES}

Arseneault R, Chien A, Newington JT, Rappon T, Harris R, Cumming RC (2013) Attenuation of LDHA expression in cancer cells leads to redox-dependent alterations in cytoskeletal structure and cell migration. Cancer Lett 338: 255-266.

Avan A, Crea F, Paolicchi E, Funel N, Galvani E, Marquez VE, Honeywell RJ, Danesi R, Peters GJ, Giovannetti E (2012) Molecular mechanisms involved in the synergistic interaction of the EZH2 inhibitor 3-deazaneplanocin A with gemcitabine in pancreatic cancer cells. Mol Cancer Ther 11: 1735-1746.

Avan A, Quint K, Nicolini F, Funel N, Frampton AE, Maftouh M, Pelliccioni S, Schuurhuis GJ, Peters GJ, Giovannetti E (2013) Enhancement of the antiproliferative activity of Gemcitabine by modulation of C-Met pathway in pancreatic cancer. Curr Pharm Des 19: 940-950.

Baumann F, Leukel P, Doerfelt A, Beier CP, Dettmer K, Oefner PJ, Kastenberger M, Kreutz M, Nickl-Jockschat T, Bogdahn U, Bosserhoff AK, Hau P (2009) Lactate promotes glioma migration by TGF-beta2-dependent regulation of matrix metalloproteinase-2. Neuro Oncol 11: 368-380.

Bijnsdorp IV, Giovannetti E, Peters GJ (2011) Analysis of drug interactions. Methods Mol Biol 731: 421-434.

Brooks GA, Dubouchaud H, Brown M, Sicurello JP, Butz CE (1999) Role of mitochondrial lactate dehydrogenase and lactate oxidation in the intracellular lactate shuttle. Proc Natl Acad Sci USA 96: 1129-1134.

Brown JM, Giaccia AJ (1998) The unique physiology of solid tumors: opportunities (and problems) for cancer therapy. Cancer Res 58: 1408-1416. 
Chang Q, Jurisica I, Do T, Hedley DW (2011) Hypoxia predicts aggressive growth and spontaneous metastasis formation from orthotopically grown primary xenografts of human pancreatic cancer. Cancer Res 71: 3110-3120.

Chen EH, Johnston 2nd EE, Vetter SM, Mitchell BS (1995) Characterization of the deoxycytidine kinase promoter in human lymphoblast cell lines. $J$ Clin Invest 95: 1660-1668.

Chien W, Lee DH, Zheng Y, Wuensche P, Alvarez R, Wen DL, Aribi AM, Thean SM, Doan NB, Said JW, Koeffler HP (2013) Growth inhibition of pancreatic cancer cells by Histone Deacetylase inhibitor belinostat through suppression of multiple pathways including HIF, NFkB, and mTOR signaling in vitro and in vivo. Mol Carcinog 2013; e-pub ahead of print 8 March 2013; doi:10.1002/mc.22024.

Duffy JP, Eibl G, Reber HA, Hines OJ (2003) Influence of hypoxia and neoangiogenesis on the growth of pancreatic cancer. Mol Cancer 2: 12.

Elnaggar M, Giovannetti E, Peters GJ (2012) Molecular targets of gemcitabine action: rationale for development of novel drugs and drug combinations. Curr Pharm Des 18: 2811-2829.

Fantin VR, St-Pierre J, Leder P (2006) Attenuation of LDH-A expression uncovers a link between glycolysis, mitochondrial physiology, and tumour maintenance. Cancer Cell 9: 425-434.

Feig C, Gopinathan A, Neesse A, Chan DS, Cook N, Tuveson DA (2012) The pancreas cancer microenvironment. Clin Cancer Res 18: 4266-4276.

Fischer K, Hoffmann P, Voelkl S, Meidenbauer N, Ammer J, Edinger M, Gottfried E, Schwarz S, Rothe G, Hoves S, Renner K, Timischl B, Mackensen A, Kunz-Schughart L, Andreesen R, Krause SW, Kreutz M (2007) Inhibitory effect of tumour cell-derived lactic acid on human T cells. Blood 109: 3812-3819.

Gatenby RA, Gillies RJ (2004) Why do cancers have high aerobic glycolysis? Nat Rev Cancer 4: 891-899.

Giovannetti E, Funel N, Peters GJ, Del Chiaro M, Erozenci LA, Vasile E, Leon LG, Pollina LE, Groen A, Falcone A, Danesi R, Campani D, Verheul HM, Boggi U (2010) MicroRNA-21 in pancreatic cancer: correlation with clinical outcome and pharmacologic aspects underlying its role in the modulation of gemcitabine activity. Cancer Res 70: 4528-4538.

Giovannetti E, Lemos C, Tekle C, Smid K, Nannizzi S, Rodriguez JA, Ricciardi S, Danesi R, Giaccone G, Peters GJ (2008) Molecular mechanisms underlying the synergistic interaction of erlotinib, an epidermal growth factor receptor tyrosine kinase inhibitor, with the multitargeted antifolate pemetrexed in non-small-cell lung cancer cells. Mol Pharmacol 73: 1290-1300.

Giovannetti E, Mey V, Danesi R, Basolo F, Barachini S, Deri M, Del Tacca M (2005) Interaction between gemcitabine and topotecan in human non-small-cell lung cancer cells: effects on cell survival, cell cycle and pharmacogenetic profile. Br J Cancer 92: 681-689.

Giovannetti E, Zucali PA, Assaraf YG, Leon LG, Smid K, Alecci C, Giancola F, Destro A, Gianoncelli L, Lorenzi E, Roncalli M, Santoro A, Peters GJ (2011) Preclinical emergence of vandetanib as a potent antitumour agent in mesothelioma: molecular mechanisms underlying its synergistic interaction with pemetrexed and carboplatin. Br J Cancer 105: $1542-1553$

Goldberg E (1985) Reproductive implications of LDH-C4 and other testis-specific isozymes. Exp Clin Immunogenet 2: 120-124.

Goldman RD, Kaplan NO, Hall TC (1964) Lactic Dehydrogenase in Human Neoplastic Tissues. Cancer Res 24: 389-399.

Graeber TG, Osmanian C, Jacks T, Housman DE, Koch CJ, Lowe SW, Giaccia AJ (1996) Hypoxia-mediated selection of cells with diminished apoptotic potential in solid tumours. Nature 379: 88-89.

Granchi C, Bertini S, Macchia M, Minutolo F (2011a) Inhibitors of lactate dehydrogenase isoforms and their therapeutic potentials. Curr Med Chem 17: 672-697.

Granchi C, Calvaresi EC, Tuccinardi T, Paterni I, Macchia M, Martinelli A, Hergenrother PJ, Minutolo F (2013) Assessing the differential action on cancer cells of LDH-A inhibitors based on the N-hydroxyindole-2-carboxylate (NHI) and malonic (Mal) scaffolds. Org Biomol Chem 11: 6588-6596.

Granchi C, Roy S, De Simone A, Salvetti I, Tuccinardi T, Martinelli A, Macchia M, Lanza M, Betti L, Giannaccini G, Lucacchini A, Giovannetti E, Sciarrillo R, Peters GJ, Minutolo F (2011b) N-Hydroxyindole-based inhibitors of lactate dehydrogenase against cancer cell proliferation. Eur J Med Chem 46: 5398-5407.

Granchi C, Roy S, Giacomelli C, Macchia M, Tuccinardi T, Martinelli A, Lanza M, Betti L, Giannaccini G, Lucacchini A, Funel N, León LG, Giovannetti E, Peters GJ, Palchaudhuri R, Calvaresi EC, Hergenrother PJ, Minutolo F (2011c) Discovery of N-hydroxyindole-based inhibitors of human lactate dehydrogenase isoform A (LDH-A) as starvation agents against cancer cells. J Med Chem 54: 1599-1612.

Haas M, Heinemann V, Kullmann F, Laubender RP, Klose C, Bruns CJ, Holdenrieder S, Modest DP, Schulz C, Boeck S (2013) Prognostic value of CA 19-9, CEA, CRP, LDH and bilirubin levels in locally advanced and metastatic pancreatic cancer: results from a multicenter, pooled analysis of patients receiving palliative chemotherapy. J Cancer Res Clin Oncol 139: 681-689.

Hanahan D, Weinberg RA (2011) Hallmarks of cancer: the next generation. Cell 144: 646-674.

Harris AL (2002) Hypoxia-A key regulatory factor in tumor growth. Nat Rev Cancer 2: 38-47.

Hashimoto O, Shimizu K, Semba S, Chiba S, Ku Y, Yokozaki H, Hori Y (2011) Hypoxia induces tumor aggressiveness and the expansion of CD133-positive cells in a hypoxia-inducible factor- $1 \alpha$-dependent manner in pancreatic cancer cells. Pathobiology 78: 181-192.

Heinemann V, Haas M, Boeck S (2012) Systemic treatment of advanced pancreatic cancer. Cancer Treat Rev 38: 843-853.

Hiraoka N, Ino Y, Sekine S, Tsuda H, Shimada K, Kosuge T, Zavada J, Yoshida M, Yamada K, Koyama T, Kanai Y (2010) Tumour necrosis is a postoperative prognostic marker for pancreatic cancer patients with a high interobserver reproducibility in histological evaluation. Br J Cancer 103: 1057-1065.

Kanno T, Sudo K, Maekawa M, Nishimura Y, Ukita M, Fukutake K (1988) Lactate dehydrogenase M-subunit deficiency: a new type of hereditary exertional myopathy. Clin Chim Acta 173: 89-98.

Kolev Y, Uetake H, Takagi Y, Sugihara K (2008) Lactate dehydrogenase-5 (LDH-5) expression in human gastric cancer: association with hypoxia-inducible factor (HIF-1R) pathway, angiogenic factors production and poor prognosis. Ann Surg Oncol 15: 2336-2344.

Koong AC, Mehta VK, Le QT, Fisher GA, Terris DJ, Brown JM, Bastidas AJ, Vierra M (2000) Pancreatic tumors show high levels of hypoxia. Int J Radiat Oncol Biol Phys 48: 919-922.

Koukourakis MI, Giatromanolaki A, Simopoulos C, Polychronidis A, Sivridis E (2005) Lactate dehydrogenase 5 (LDH5) relates to up-regulated hypoxia inducible factor pathway and metastasis in colorectal cancer. Clin Exp Metastasis 22: 25-30.

Koukourakis MI, Pitiakoudis M, Giatromanolaki A, Tsarouha A, Polychronidis A, Sivridis E, Simopoulos C (2006) Oxygen and glucose consumption in gastrointestinal adenocarcinomas: correlation with markers of hypoxia, acidity and anaerobic glycolysis. Cancer Sci 97: 1056-1060.

Lam W, Bussom S, Cheng YC (2009) Effect of hypoxia on the expression of phosphoglycerate kinase and antitumor activity of troxacitabine and gemcitabine in non-small cell lung carcinoma. Mol Cancer Ther 8: 415-423.

Le A, Cooper CR, Gouw AM, Dinavahi R, Maitra A, Deck LM, Royer RE, Vander Jagt DL, Semenza GL, Dang CV (2010) Inhibition of lactate dehydrogenase $\mathrm{A}$ induces oxidative stress and inhibits tumor progression. Proc Natl Acad Sci USA 107: 2037-2042.

Le QT, Denko NC, Giaccia AJ (2004) Hypoxic gene expression and metastasis. Cancer Metastasis Rev 23: 293-310.

Longati P, Jia X, Eimer J, Wagman A, Witt MR, Rehnmark S, Verbeke C, Toftgård R, Löhr M, Heuchel RL (2013) 3D pancreatic carcinoma spheroids induce a matrix-rich, chemoresistant phenotype offering a better model for drug testing. BMC Cancer 13: 95.

Manerba M, Vettraino M, Fiume L, Di Stefano G, Sartini A, Giacomini E, Buonfiglio R, Roberti M, Recanatini M (2012) Galloflavin (CAS 568-80-9): a novel inhibitor of lactate dehydrogenase. Chem Med Chem 7: 311-317.

Metallo CM, Gameiro PA, Bell EL, Mattaini KR, Yang J, Hiller K, Jewell CM, Johnson ZR, Irvine DJ, Guarente L, Kelleher JK, Vander Heiden MG, Iliopoulos O, Stephanopoulos G (2011) Reductive glutamine metabolism by IDH1 mediates lipogenesis under hypoxia. Nature 481: 380-384.

Padrón JM, van der Wilt CL, Smid K, Smitskamp-Wilms E, Backus HH, Pizao PE, Giaccone G, Peters GJ (2000) The multilayered postconfluent cell culture as a model for drug screening. Crit Rev Oncol Hematol 36: 141-157.

Patel JH, Loboda AP, Showe MK, Showe LC, McMahon SB (2004) Analysis of genomic targets reveals complex functions of MYC. Nat Rev Cancer 4: $562-568$.

Salnikov AV, Liu L, Platen M, Gladkich J, Salnikova O, Ryschich E, Mattern J, Moldenhauer G, Werner J, Schemmer P, Büchler MW, Herr I (2002) Hypoxia induces EMT in low and highly aggressive pancreatic tumor cells but only cells with cancer stem cell characteristics acquire pronounced migratory potential. PLoS One 7: e46391. 
Semenza GL (2007) Oxygen-dependent regulation of mitochondrial respiration by hypoxia-inducible factor 1 . Biochem J 405: 1-9.

Siegel R, Naishadham D, Jemal A (2012) Cancer statistics, 2012. CA Cancer J Clin 62: 10-29.

Sun HX, Xu Y, Yang XR, Wang WM, Bai H, Shi RY, Nayar SK, Devbhandari RP, He YZ, Zhu QF, Sun YF, Hu B, Khan M, Anders RA, Fan J (2013) Hypoxia inducible factor 2 alpha inhibits hepatocellular carcinoma growth through the transcription factor dimerization partner 3/E2F transcription factor 1-dependent apoptotic pathway. Hepatology 57: 1088-1097.

Swietach P, Vaughan-Jones RD, Harris AL (2007) Regulation of tumor pH and the role of carbonic anhydrase 9. Cancer Metastasis Rev 26: 299-310.

Vasseur S, Tomasini R, Tournaire R, Iovanna JL (2010) Hypoxia induced tumour metabolic switch contributes to pancreatic cancer aggressiveness. Cancers 2: 2138-2152.

Verma A, Wang H, Manavathi B, Fok JY, Mann AP, Kumar R, Mehta K (2006) Increased expression of tissue transglutaminase in pancreatic ductal adenocarcinoma and its implications in drug resistance and metastasis. Cancer Res 66: 10525-10533.

Whipple C, Korc M (2008) Targeting angiogenesis in pancreatic cancer: rationale and pitfalls. Langenbecks Arch Surg 393: 901-910.

Wilson WR, Hay MP (2011) Targeting hypoxia in cancer therapy. Nat Rev Cancer 11: 393-410.

Wouters A, Pauwels B, Lambrechts HA, Pattyn GG, Ides J, Baay M, Meijnders P, Peeters M, Vermorken JB, Lardon F (2011) Retention of the in vitro radiosensitizing potential of gemcitabine under anoxic conditions, in p53 wild-type and p53-deficient non-small-cell lung carcinoma cells. Int J Radiat Oncol Biol Phys 80: 558-566.

Xie H, Valera VA, Merino MJ, Amato AM, Signoretti S, Linehan WM, Sukhatme VP, Seth P (2009) LDH-A inhibition, a therapeutic strategy for treatment of hereditary leiomyomatosis and renal cell cancer. Mol Cancer Ther 8: 626-635.

Yokoi K, Fidler IJ (2004) Hypoxia increases resistance of human pancreatic cancer cells to apoptosis induced by gemcitabine. Clin Cancer Res 10: 2299-2306.

Zhang X, Galardi E, Duquette M, Delic M, Lawler J, Parangi S (2005) Antiangiogenic treatment with the three thrombospondin-1 type 1 repeats recombinant protein in an orthotopic human pancreatic cancer model. Clin Cancer Res 11: 2337-2344.

Zhao D, Zou SW, Liu Y, Zhou X, Mo Y, Wang P, Xu YH, Dong B, Xiong Y, Lei QY, Guan KL (2013) Lysine-5 acetylation negatively regulates lactate dehydrogenase A and is decreased in pancreatic cancer. Cancer Cell 23: 464-476.

Zhou M, Zhao Y, Ding Y, Liu H, Liu Z, Fodstad O, Riker AI, Kamarajugadda S, Lu J, Owen LB, Ledoux SP, Tan M (2010) Warburg effect in chemosensitivity: targeting lactate dehydrogenase-A re-sensitizes taxol-resistant cancer cells to taxol. Mol Cancer 9: 33.

Zhou W, Capello M, Fredolini C, Piemonti L, Liotta LA, Novelli F, Petricoin EF (2011) Proteomic analysis of pancreatic ductal adenocarcinoma cells reveals metabolic alterations. J Proteome Res 10: 1944-1952.

This work is published under the standard license to publish agreement. After 12 months the work will become freely available and the license terms will switch to a Creative Commons AttributionNonCommercial-Share Alike 3.0 Unported License.

Supplementary Information accompanies this paper on British Journal of Cancer website (http://www.nature.com/bjc) 